\title{
Editorial
}

\section{5-Year Anniversary of Model Assisted Statistics and Applications (MASA)}

\author{
Stan Lipovetsky \\ MASA Co-Editor-in-Chief
}

Dear Authors, Editors, Board Members, Reviewers, Readers, and Friends of MASA - Congratulations on the 15-Year Anniversary of the Journal! Countless thanks to All for your great contribution, support, and efforts on behalf of MASA.

Originally founded in 2005 by Professor Sarjinder Singh, Editor-in-Chief, MASA has become a renowned journal in statistics community all around the world. Earlier editorial articles in MASA v.4, \#1, 2009, and v.10, \#1, 2010, described distributions of the published papers by the continents and main topics. Completing those tables with the works up to the end of 2020, we can present the updated annual distributions in Tables 1 and 2.

Table 1

Distribution by continents in each year (100\% in row), 2005-2020

\begin{tabular}{cccccccc}
\hline Year & Volume & Africa & Americ & Asia & Australi & Europe & Tota \\
\hline $2005-6$ & 1 & 6 & 15 & 49 & 12 & 18 & 100 \\
2007 & 2 & 0 & 37 & 49 & 4 & 11 & 100 \\
2008 & 3 & 4 & 28 & 66 & 0 & 4 & 100 \\
2009 & 4 & 0 & 57 & 24 & 4 & 15 & 100 \\
2010 & 5 & 3 & 53 & 37 & 0 & 7 & 100 \\
2011 & 6 & 3 & 20 & 57 & 0 & 21 & 100 \\
2012 & 7 & 3 & 39 & 38 & 0 & 20 & 100 \\
2013 & 8 & 0 & 34 & 60 & 0 & 7 & 100 \\
2014 & 9 & 4 & 17 & 55 & 0 & 24 & 100 \\
2015 & 10 & 5 & 11 & 62 & 14 & 8 & 100 \\
2016 & 11 & 7 & 14 & 46 & 4 & 29 & 100 \\
2017 & 12 & 0 & 45 & 45 & 0 & 10 & 100 \\
2018 & 13 & 9 & 27 & 36 & 3 & 24 & 100 \\
2019 & 14 & 4 & 61 & 9 & 4 & 22 & 100 \\
2020 & 15 & 4 & 36 & 32 & 0 & 28 & 100 \\
\hline
\end{tabular}

By Table 1, Asian countries contribute in the big proportion, that roughly corresponds to the distribution of the whole mankind population.

By Table 2, distribution based on keywords is obtained for the main subjects of papers. It shows that less works in the recent years were devoted to the survey sampling techniques, testing, estimation, and computation problems, while regressions and other multivariate methods of modeling, as well as general methodology and applications attract more attention.

Total more than a half a thousand selected papers have been published in MASA. To make MASA more visible among multiple other journals on statistics, we increased the requirements to higher theoretical level and real practical applications of the papers. MASA is abstracted and indexed in the following sources on a journal performance: 
Table 2

Distribution of the papers by the subject (100\% for each row), 2005-2020

\begin{tabular}{|c|c|c|c|c|c|c|}
\hline Year & Volume & $\begin{array}{c}\text { Survey Sampling, } \\
\text { Randomized response } \\
\text { Non-response, Design }\end{array}$ & $\begin{array}{c}\text { Tests, Distributions, } \\
\text { Estimation, Imputation } \\
\text { Computation }\end{array}$ & $\begin{array}{l}\text { Regression, Classification, } \\
\text { Multivariate methods, Nets, } \\
\text { Machine Learning, AI }\end{array}$ & $\begin{array}{l}\text { Applications, } \\
\text { General } \\
\text { Methodology }\end{array}$ & Total \\
\hline $2005-6$ & 1 & 46 & 28 & 11 & 16 & 100 \\
\hline 2007 & 2 & 24 & 36 & 17 & 25 & 101 \\
\hline 2008 & 3 & 37 & 39 & 12 & 13 & 100 \\
\hline 2009 & 4 & 8 & 51 & 22 & 18 & 100 \\
\hline 2010 & 5 & 20 & 37 & 37 & 7 & 100 \\
\hline 2011 & 6 & 23 & 44 & 15 & 18 & 100 \\
\hline 2012 & 7 & 16 & 41 & 20 & 23 & 100 \\
\hline 2013 & 8 & 28 & 51 & 17 & 3 & 100 \\
\hline 2014 & 9 & 35 & 27 & 17 & 20 & 100 \\
\hline 2015 & 10 & 54 & 11 & 27 & 8 & 100 \\
\hline 2016 & 11 & 25 & 43 & 18 & 14 & 100 \\
\hline 2017 & 12 & 13 & 26 & 32 & 29 & 100 \\
\hline 2018 & 13 & 6 & 12 & 52 & 30 & 100 \\
\hline 2019 & 14 & 17 & 17 & 48 & 17 & 100 \\
\hline 2020 & 15 & 12 & 20 & 48 & 20 & 100 \\
\hline
\end{tabular}

ABDC Journal Quality List, Cabell's Guide or Directory, Current Index to Statistics, Google Scholar, Mathematical Reviews, MathSciNet, Scopus, Ulrich's Periodicals Directory, Zentralblatt MATH, see also at the website: http://www.scimagojr.com/journalsearch.php?q=7100153149\&tip=sid

Periodically we organize thematical special issues on main topics of modern statistical research:

Statistical Inference with Missing Data (v.3, \#2, 2008),

Statistics in Marketing and Advertising Research (v.4, \#3, 2009),

Teaching Statistics (v.4, \#4, 2009),

Statistical Models in Bio-Medicine (v.5, \#3, 2010),

Statistics in Decision Making (v.5, \#4, 2010),

Statistical Methods in Optimization and Operations Research (v.6, \#3, 2011),

Modern Applications of Copula and Financial Modeling (v.7, \#4, 2012),

Statistics in Medical Research (v.8, \#2, 2013),

Randomized Response Techniques (v.9, \#1, 2014),

Statistical Estimations in Complex Problems (v.9, \#3, 2014),

Estimation, Testing and Forecasting in Econometrics (v.10, \#3, 2015),

50-th year of the Warner's Randomized Response Model (v.10, \#4, 2015),

Machine Learning in Applied Statistics (v.12, \#3, 2017),

Statistical Models in Finance and Insurance (v.12, \#4, 2017),

SAS Global Forum (v.13, \#4, 2018),

Multivariate Statistics in Applications to Econometrics (v.15, \#4, 2020),

Statistical Modeling of Covid-19 and Pandemics (v.16, \#1, 2021).

Many years Prof. Sarjinder Singh presents his marvelous editorial reports about the JSM - Joint Statistical Meetings of the American Statistical Association, attended regularly by 6-7 thousand statisticians and practitioners from academia, government, industries, and from different countries. Sarjinder holds a regular booth "STATHAWKERS" at the books Exhibitions there, and illustrates his JSM memories and meetings with colleagues by multiple pictures that makes MASA even more attractive - see, for instance, in MASA v.7, \#4, 2012; v.8, \#4, 2013; v.12,\#1, 2017; v.13,\#1, 2018; and v.14, \#4, 2019. Each volume's last issue expresses our gratitude to the reviewers and editors helping in the work of the journal.

MASA is continuing to present various modern statistical models, problems, and applications, supporting practical usage of new statistical techniques. This way our journal is becoming a really outstanding international source of Model Assisted Statistics and Applications.

Some useful links to the journal are:

www.iospress.com/model-assisted-statistics-and-applications, or www.tiny.cc/MASjournal.

Newsletter: The link to sign-up to the mailing list is www.tiny.cc/MAS-signup. 